\title{
PERCEPÇÃO AMBIENTAL DE ESTUDANTES DO 6 ANO DO ENSINO FUNDAMENTAL SOBRE O MEIO AMBIENTE
}

\author{
Suzianne Costa Silva ${ }^{1}$
}

\author{
Adriana Araújo Pompeu Piza²
}

Francisco César Brito Vieira ${ }^{3}$

RESUMO. O estudo do meio ambiente é importante para compreender melhor as inter-relações entre o homem e o ambiente e suas expectativas, satisfações e insatisfações, julgamentos e condutas. Saber qual é a percepção de estudantes do $6^{\circ}$ ano do ensino fundamental sobre o meio ambiente em que vivem através de atividade extra-classe, possibilita a esse estudante vivenciar o que aprendeu na sala de aula. Este trabalho teve como estratégia didática não apenas o entendimento do que o indivíduo percebe, mas com o objetivo de promover a sensibilização, bem como o desenvolvimento do sistema de percepção e compreensão do ambiente para a formação de um conceito e transformação do ambiente em que vive. Assim, espera-se contribuir com o desenvolvimento de um ensino-aprendizagem mais eficiente e voltado à sua realidade. A pesquisa foi realizada com estudantes do $6^{\circ}$ ano do ensino fundamental da Escola Municipal Vicente Cruz, situada na Zona Norte de Manaus. Para isso utilizou-se o método de estudo de caso e a pesquisa participante, através da utilização do recurso da máquina fotográfica com dinâmica de foto-interpretação, frases conceituais, mapas mentais e debate. Os procedimentos de análise foram qualitativos e quantitativos por meio de tabelas e gráficos. Os resultados mostram que no conceito formado

\footnotetext{
1 Professora do $1^{\circ}$ ao $5^{\circ}$ ano do ensino fundamental da rede pública municipal. Pós graduada em psicopedagogia institucional pela faculdade IDEIA / FAEL.

${ }^{2}$ Licenciada em Biologia pela Faculdade Nilton Lins, Pós graduada em Educação Ambiental pela Este e Mestra em ensino de Ciências na Amazônia, pela Universidade do Estado do Amazonas / UEA. Professora de ciências da rede pública municipal do $6 \div$ ao 9 ํㅡ ano do ensino fundamental.

${ }^{3}$ Mestre em ensino de ciências na Amazônia, formado Universidade do Estado do Amazonas / UEA. Professor de ciências da rede pública municipal do $6^{\circ}$ ao $9^{\circ}$ ano do ensino fundamental.
} 
pelos alunos, eles não se vêem como parte integrante do meio ambiente e como modificadores dele, acreditavam que o meio ambiente era tudo que estivesse ao alcance de ser utilizado, ou seja, o natural. Após a participação desta atividade, os estudantes passaram a entender o papel do ser humano dentro do meio ambiente e sua complexidade, reformulando o conceito pré-estabelecido.

Palavras chaves: Meio Ambiente, Percepção, Estudantes.

\section{INTRODUÇÃO}

A Educação Ambiental está inserida nos Parâmetros Curriculares Nacionais (PCN's) das escolas, isto surgiu diante da preocupação com a formação de atitudes relacionadas a esta temática. A escola proporciona mudanças de atitudes de seus alunos com relação ao ambiente, pois, tem procurado através de diferentes disciplinas, proporcionar informações relativas ao meio ambiente.

O homem está constantemente agindo sobre o meio com o objetivo de sanar suas necessidades e desejos. Cada indivíduo percebe, reage e responde diferen€temente frente às ações sobre o meio. Os conceitos formados ou suas manifestações são, portanto resultado das percepções, dos processos cognitivos, julgamentos e expectativas de cada indivíduo. Embora nem todas as manifestações psicológicas sejam evidentes, são constantes, e afetam nossa conduta, na maioria das vezes, inconscientemente.

Assim, o estudo do meio ambiente é de fundamental importância para que possamos compreender melhor as inter-relações entre o homem e o ambiente, suas expectativas, satisfações e insatisfações, julgamentos e condutas (FAGGIONATO, 2002). Saber como os alunos de ensino fundamental conceituam o ambiente em que vivem suas fontes de satisfação e insatisfação é de fundamental importância, pois possibilita a realização de um trabalho com bases locais, partindo da realidade do público alvo.

Este trabalho teve como estratégia didática não apenas o entendimento do que o indivíduo percebe (conceito pessoal), mas promover a sensibilização, bem como o desenvolvimento do sistema de percepção e compreensão do ambiente nos estudantes 
em questão. Assim, espera-se contribuir com o desenvolvimento de um ensinoaprendizagem mais eficiente e adequado à realidade. Segundo Ferrara (1999), diversas são as formas de se estudar a percepção ambiental: questionários, mapas mentais e representação fotográfica.

A percepção ambiental pode ser entendida como a representação (oral, gráfica e corporal) do ambiente, onde o lugar é o veículo de acontecimentos emocionalmente fortes ou percebidos como um símbolo (TUAN, 1974). Segundo J. Filho et al (1995), a escola é o meio ideal para o desenvolvimento de uma consciência sobre um determinado assunto. Por meio do estímulo dos professores, os alunos poderão refletir sobre temas atuais, passando de agentes passivos a ativos, visando considerar sua história, valorizar sua terra e preservar o meio ambiente.

\section{LOCAL E MATERIAL DA PESQUISA}

A escola escolhida para a pesquisa foi a Escola Municipal Vicente Cruz, localizada na Avenida Torquato Tapajós s/n Km 12 no bairro de Flores, Manaus - AM. Foi fundada em 12 de janeiro de 1962, na Loja Maçônica Simbólica Amazonas, Educandos. Seu nome provém da homenagem feita ao venerável da loja, Sr. Vicente Cruz. Atualmente a maioria dos alunos é oriunda de algumas invasões que ocorreram nas proximidades da escola. Entre elas as invasões Parque Riachuelo, "Jesus me deu", Invasão da antiga Carbrás (hoje Parque São Pedro), Santo Antônio, Parque Rio Solimões, Rio Piorini e Campos Sales, localizados na zona Norte. E os demais alunos são moradores dos ramais localizados nos ramais das rodovias AM-010 e BR-174.

A atividade foi realizada especificamente com 32 estudantes de uma turma do $6^{\circ}$ ano do ensino fundamental do turno matutino. Primeiramente, a abordagem foi feita através de construção de frases relacionadas ao conceito de meio ambiente, 0 acompanhamento foi feito pela autora do presente trabalho e também professora de Ciências da escola supra citada, turno matutino e dos estudantes em questão. As respostas do questionamento escrito foram analisadas por estatística descritiva e dispostas em gráficos para melhor visualização. 


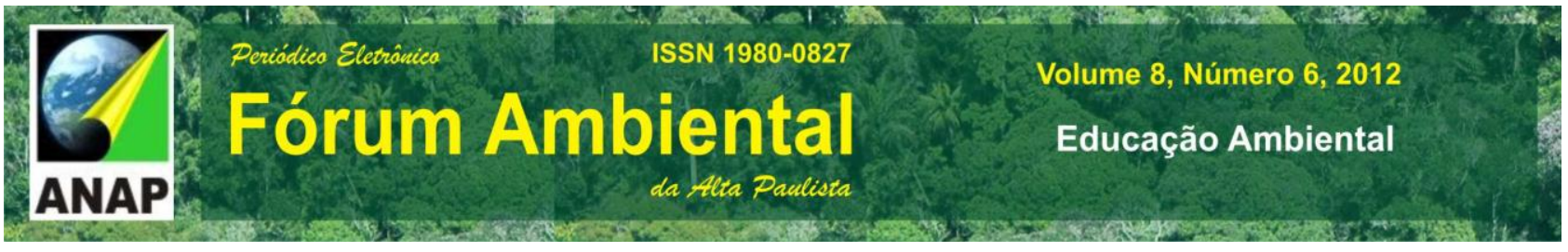

Posteriormente foi tratada a percepção ambiental de forma pré-verbal, isto é, apenas observar o que os estudantes queriam revelar dos seus valores sem, no entanto, exigir suas expressões verbais. Para isso foi utilizado o recurso da máquina fotográfica, quando os mesmos estudantes selecionados foram convidados a fotografar as imediações da sua escola e da sua casa, com a finalidade de registrar tudo aquilo que sua percepção indicasse sobre a realidade do meio ambiente, ou tudo aquilo que tivesse importância sobre a realidade do meio ambiente local. A atividade foi controlada de forma a dirigir a percepção dos alunos ao que eles representariam como sendo meio ambiente.

Foram utilizadas oito máquinas fotográficas descartáveis FUJI com filme de 27 poses cada uma. Cada máquina foi utilizada por quatro estudantes, um de cada vez, 6 fotos por estudante, totalizando 192 fotografias. Para o maior esclarecimento de parâmetros de comparação com maior discernimento entre as fotos produzidas, solicitouse o registro fotográfico dos seis locais ou situações que na percepção dos alunos era considerado meio ambiente, seja limpo ou poluído. Outro recurso utilizado foram os mapas mentais, onde os estudantes foram solicitados a colocar no papel a imagem que tinham na mente a respeito de meio ambiente, ou seja, fazer um desenho.

Após essas etapas foi realizada uma aula expositiva sobre a temática meio ambiente, onde os resultados obtidos pela classe foram discutidos de maneira que os estudantes puderam perceber alguns erros que cometeram ao conceituar meio ambiente. Todos os participantes da pesquisa foram convidados a comparecer a exposição das fotos, mapas mentais e frases, que foi realizada no pátio da Escola Municipal Vicente Cruz. As fotos foram montadas em painéis e os "fotógrafos" tiveram a oportunidade de explicar a sua produção e as razões da escolha das situações fotográficas, tendo em vista o tema abordado - meio ambiente. Depois da exposição de cada fotógrafo, foi concedido um tempo para discussão de modo a estimular o diálogo entre os estudantes da escola e promover a troca de impressões sobre o material fotográfico.

Os estudantes foram solicitados a formar uma frase sobre o que é meio ambiente, as respostas predominantes são a seguir apresentadas: "Meio ambiente é um lugar cheio de plantas, animais, rios, árvores e tudo limpo", "Meio Ambiente é tudo que existe na floresta, árvores, lagos, rios, e tudo que tem em qualquer estado ou cidade, e todos nós temos que preservar e cuidar muito bem", "Meio Ambiente é um ambiente muito limpo e 
preservado sem nenhum lixo no chão". Os conceitos ficam na mesma linha, todos os estudantes lembraram do meio ambiente natural, mas não viram o ser humano como parte dele e como agente transformador desse meio.

Do total de 192 fotos, 155 (80,72\%) tiveram boa qualidade de imagem e 37 $(19,27 \%)$ apresentaram defeito de imagem e foram descartadas. Portanto levando em consideração somente as fotos com boa qualidade, observou-se que as fotografias se dividiram em onze categorias, cujos percentuais de quantidade está na Tabela 1 abaixo.

Tabela 1. Categorias e percentual das fotografias.

\begin{tabular}{lc}
\hline Categorias & $\%$ \\
\hline Lixo & $20,00 \%$ \\
Áreas verdes & $18,06 \%$ \\
Água & $16,77 \%$ \\
Desmatamento & $12,25 \%$ \\
Moradia & $9,67 \%$ \\
Fábricas e comércios & $7,09 \%$ \\
Rua & $5,16 \%$ \\
Ar & $3,87 \%$ \\
Condomínios & $3,22 \%$ \\
Animais & $2,58 \%$ \\
Igreja & $1,33 \%$ \\
\hline
\end{tabular}

Nas fotografias há ênfase de um desejo de denúncia contra os que insistem em jogar lixo nas ruas, apesar da coleta três vezes por semana. Essa denúncia nas fotos fezse explícita também nos debates, em que um aluno explode: "Esse povo é mal educado". Esse é o único momento em que se deslumbra a educação como uma relação humana, estabelecendo entre as pessoas uma relação de indicar o culpado, longe de qualquer atuação colaborativa. Isso faz com que o meio ambiente urbano supere a simples caracterização física ou técnica da infra-estrutura, para assumir uma dimensão 
educacional e cultural indiscutíveis. Foram muitas as fotos que focalizaram os aspectos degradantes do meio ambiente, o lixo, o igarapé sujo e esgoto a céu aberto.

Muitas imagens de florestas e matas virgens, outras de plantações e quintais com árvores frutíferas e jardins bem cuidados registraram o meio ambiente limpo. Com relação às fotos de áreas desmatadas um aluno explicou no debate

Essa era uma área de floresta fechada, mas as pessoas invadiram e desmataram tudo para construir suas casas, a polícia apareceu e expulsou todo mundo, mas o estrago já estava feito e agora essa área ficou assim cheia de entulhos. Era um meio ambiente limpo, mas agora ficou poluído (Estudante B.D. 11 anos, bairro Parque São Pedro - Carbrás, 2008).

É importante analisar o potencial das fotografias em comunicar a importância da água na infância da criança amazônica. Nada mais óbvio em uma cidade que se desenvolveu entrecortada por rios e igarapés. Isso se mostra na fala do estudante M.D. (10 anos, bairro Parque São Pedro Carbrás-2008),

Esse é o igarapé chamado Piscinão, era um banho muito legal antes da invasão da Carbrás, hoje tem lixo e cheiro forte porque a água da rua escorre pra lá, não sei como, mas ainda tem gente que pesca e toma banho nele, eu queria que fosse limpo como antes.

As fotografias mostraram a situação do bairro e das casas em que vivem, de alvenaria e a maioria de madeira, pequenas e em geral de um ou dois cômodos. Ruas de barro onde o ônibus não entra. Algumas fotos mostram a estrutura das casas e estabelece bem o limite da invasão e da área verde ainda intacta logo atrás, um verdadeiro discenso. A fala da estudante G.S.D. (12 anos, bairro Jesus Me Deu, 2008), retrata esse ambiente,

Eu fotografei o quintal da minha casa porque é um meio ambiente, mas que está sujo e bagunçado, poderia estar arrumado com árvores, grama e um parquinho, eu gostaria que ele fosse assim. Dava prá brincar com as colegas e não tinha perigo de pegar doenças.

A porcentagem de 7,09\% apresentou imagens de comércios e fábricas. Ao ver as fotos pensou-se ser um pensamento de urbanização e poluição, porém a interpretação dos estudantes foi diferente como se percebe na fala da estudante M.C.M (12 anos, Jesus Me Deu, 2008), "As fábricas da cidade tem uma estrutura bonita e grande, com jardins 
bem cuidados e verdes, acho que é um meio ambiente limpo". Somente 6 fotos (3,87\%) estavam relacionadas com a poluição do ar causada pelas queimadas na invasão ou pelas fábricas dos arredores.

Com menor participação, algumas fotos mostraram a preocupação com a segurança na moradia, os condomínios foram fotografados para mostrar os muros altos e as guaritas de segurança. Outras foram de animais domésticos como cachorro e gato. Os estudantes relataram que queriam retratar a natureza já que é difícil agora verem um animal silvestre. Duas fotos foram da igreja do bairro, de autoria de uma estudante que considera este local um meio ambiente de educação e cultura. Apenas uma foto foi tirada no interior da escola, na lateral do prédio, onde o lixo ficou amontoado e mostra as condições internas das paredes do muro.

Foi pedido aos estudantes participantes da pesquisa para desenharem a imagem que tinham na mente sobre o meio ambiente, ou seja, fazer um mapa mental. Os mapas mentais $(n=32)$ indicaram 20 amostras $(62,5 \%)$ com elementos naturais como desenhos de árvores, animais e rios; e 12 amostras (37,5\%) indicaram elementos urbanos, como edificações, lixo, meios de transporte e o ser humano, além de elementos naturais.

Aqueles estudantes que no mapa mental não evidenciaram o ser humano como parte do meio, após a realização do debate com interpretação e comentários das fotografias, passaram a ter uma visão diferente e mais coerente com a realidade. Isso pode ser observado no conceito de meio ambiente formado por escrito pelo aluno J.G. (12 anos, Jesus Me Deu, 2008), antes do debate e após o debate. Seu conceito antes do debate era

\footnotetext{
"O meio ambiente é tudo da natureza, floresta, rios e animais", e após o debate: "O meio Ambiente são as florestas, rios e animais, mas também não é só o que é relacionado com natureza, também tem outros tipos de meio ambiente como as cidades e tudo que ela ocasiona como o lixo, e nós mesmos fazemos parte do meio ambiente, e precisamos preservar ele porque sem ele não tem vida no planeta".
}

As fotos dos estudantes constituem o documento que confere validade científica à pesquisa, ao mesmo tempo em que são signos, representação da percepção ambiental dos estudantes. Assim foi possível captar a representação urbana constituída diariamente por cada um deles. Nas fotografias a maior preocupação foi em retratar ambientes 
construídos, ou seja, resultantes da interferência humana. Já os mapas mentais se referiram na sua maioria a ambientes naturais. Conclui-se que a primeira imagem que vem na mente dos estudantes sobre meio ambiente está relacionado ao ambiente natural sem interferência humana.

Oliveira (2005) obteve resultados semelhantes em sua pesquisa de dissertação, embora voltada para a saúde, à percepção ambiental dos indivíduos participantes mostrou a preocupação com a água e compararam a qualidade desse bem entre os igarapés no passado e a situação atual; a ausência de estruturas e locais para o lazer também foram reclamações constantes; assim como ocorreu com a pesquisa em questão. Jacobi (2000), em sua pesquisa de percepção, também obteve como resultado um índice muito baixo de preocupação com a poluição do ar; as principais referências de desejo de urbanização referiram-se ao asfaltamento das ruas e acesso a esgoto; os indivíduos participantes também destacaram a importância de mudar a atitude dos que despejam lixo em locais impróprios e as condições de habitabilidade foram idênticas às encontradas nesta pesquisa.

\section{CONSIDERAÇÕES FINAIS}

Como resultado obtido nessas atividades de percepção ambiental, foi notório a ampliação do conhecimento e interesse pela problemática ambiental e mudanças no comportamento, atitudes e percepção do meio. Agora, para esses estudantes, formar uma frase ou texto falando sobre o meio ambiente tornou-se algo fácil e coerente com a realidade vivenciada, já que eles passaram a se ver como parte integrante dele. Para reformar a educação é necessário repensar nosso modo de conduzir as mudanças, reformando nosso pensamento, adotando uma postura de ordem cultural e não técnica ou metodológica. É preciso reabilitar o que a separação e a fragmentação dos saberes têm ferido: o ser humano, a natureza, o cosmos e a realidade. Trata-se de promover um modo de pensar capaz de recompor o conhecimento dividido e de gerar uma nova ética na articulação entre teoria e prática, ação e saber, com o intuito de criar uma nova solidariedade entre os seres humanos. Isso pode partir, por exemplo, da consciência dos professores de enfatizar os problemas ambientais para os seus estudantes, ensinar e 
exercitar a postura correta diante das questões relacionadas ao meio ambiente em que vivemos saindo do discurso dos livros didáticos e utilizando a própria realidade dos estudantes.

\section{REFERÊNCIAS}

FAGGIONATO, Sandra. Percepção ambiental: material de apoio - textos, 2002. Disponível no site http://educar.sc.usp.br/biologia/textos/m_a_txt4.html. Acessado em 13. Dez. 2008.

FERRARA, Lucrecia D' Alessio. Olhar Periférico: informação, linguagem, percepção ambiental. São Paulo: Edusp, 1999.

FILHO, J.R.M., PEREIRA, E.D., ARAÚJO, M.L. Educação Ambiental na escola: uma experiência na escola estadual de 1ํgrau Liberdade. Monografia. NUMA/UFPA, 1995.

JACOBI, Pedro Roberto. Cidade e meio ambiente: percepções e práticas em São Paulo.1 $1^{\mathrm{a}}$ ed. São Paulo: Annablume, 2000.

OLIVEIRA, Raquel Paiva de. Ambiente e Saúde na Cidade de Manaus: Percepção dos moradores no Bairro Jorge Teixeira. Manaus, AM: dissertação UFAM, 2005.

SECRETARIA DA EDUCAÇÃO FUNDAMENTAL / MINISTÉRIO DA EDUCAÇÃO. Parâmetros Curriculares Nacionais: meio ambiente e saúde. $3^{\underline{a}}$ edição. Brasília: $A$ Secretaria, 2001.

TUAN, Y.F. Topofilia: Um estudo da Percepção, atitudes e valores do meio ambiente. São Paulo, SP: Difel, 1974. 